ARTICLE

https://doi.org/10.1038/s41467-018-08253-z

\title{
Use of trifluoroacetaldehyde N-tfsylhydrazone as a trifluorodiazoethane surrogate and its synthetic applications
}

Xinyu Zhang ${ }^{1}$, Zhaohong Liu ${ }^{1}$, Xiangyu Yang ${ }^{1}$, Yuanqing Dong ${ }^{1}$, Matteo Virelli ${ }^{2}$, Giuseppe Zanoni ${ }^{2}$, Edward A. Anderson (D ${ }^{3} \&$ Xihe $\mathrm{Bi}^{1,4}$

Trifluorodiazoethane $\left(\mathrm{CF}_{3} \mathrm{CHN}_{2}\right)$, a highly reactive fluoroalkylating reagent, offers a useful means to introduce trifluoromethyl groups into organic molecules. At present, $\mathrm{CF}_{3} \mathrm{CHN}_{2}$ can only be generated by oxidation of trifluoroethylamine hydrochloride under acidic conditions; due to its toxic and explosive nature, its safe generation and use remains a prominent concern, hampering wider synthetic exploitation. Here we report the development of trifluoroacetaldehyde $\mathrm{N}$-tfsylhydrazone (TFHZ-Tfs) as a $\mathrm{CF}_{3} \mathrm{CHN}_{2}$ surrogate, which is capable of generating $\mathrm{CF}_{3} \mathrm{CHN}_{2}$ in situ under basic conditions. The reaction conditions employed in this chemistry enabled a difluoroalkenylation of $\mathrm{X}-\mathrm{H}$ bonds $(X=N, \mathrm{O}, \mathrm{S}, \mathrm{Se})$, affording a wide range of heteroatom-substituted gem-difluoroalkenes, along with Doyle-Kirmse rearrangements and trifluoromethylcyclopropanation reactions, with superior outcomes to approaches using pre-formed $\mathrm{CF}_{3} \mathrm{CHN}_{2}$. Given the importance of generally applicable fluorination methodologies, the use of TFHZ-Tfs thus creates opportunities across organic and medicinal chemistry, by enabling the wider exploration of the reactivity of trifluorodiazoethane.

\footnotetext{
${ }^{1}$ Department of Chemistry, Northeast Normal University, 130024 Changchun, China. ${ }^{2}$ Department of Chemistry, University of Pavia, Viale Taramelli 12 , 27100 Pavia, Italy. ${ }^{3}$ Chemistry Research Laboratory, University of Oxford, 12 Mansfield Road, Oxford OX1 3TA, UK. ${ }^{4}$ State Key Laboratory of ElementoOrganic Chemistry, Nankai University, 300071 Tianjin, China. These authors contributed equally: Xinyu Zhang, Zhaohong Liu. Correspondence and requests for materials should be addressed to X.B. (email: bixh507@nenu.edu.cn)
} 
T rifluorodiazoethane $\left(\mathrm{CF}_{3} \mathrm{CHN}_{2}\right.$, also known as trifluoromethyldiazomethane) is a highly reactive trifluoromethylating agent employed in transformations such as cycloadditions ${ }^{1-6}, \mathrm{X}-\mathrm{H}$ insertions $\mathrm{s}^{7,8}$, coupling reactions ${ }^{9,10}$ and homologations (Fig. 1a) $)^{11,12} \cdot \mathrm{CF}_{3} \mathrm{CHN}_{2}$ is generated by the oxidation of trifluoroethylamine hydrochloride $\left(\mathrm{CF}_{3} \mathrm{CH}_{2} \mathrm{NH}_{2} \cdot \mathrm{HCl}\right)$ under acidic conditions, but being a toxic and explosive gas, handling of $\mathrm{CF}_{3} \mathrm{CHN}_{2}$ at room temperature is extremely hazardous if a significant buildup occurs ${ }^{2,13}$. Although first described in $1943^{14}$, only in the last decade have improvements to this method been made, involving slow addition of aqueous $\mathrm{NaNO}_{2}$ to trifluoroethylamine to avoid an accumulation of large amounts of $\mathrm{CF}_{3} \mathrm{CHN}_{2}{ }^{2}$. More recently, other operational improvements have been developed, such as the small-scale preparation of $\mathrm{CF}_{3} \mathrm{CHN}_{2}$ in solution ${ }^{5,7,8}$, the recycling of gaseous $\mathrm{CF}_{3} \mathrm{CHN}_{2}{ }^{9}$, and the use of continuous-flow chemistry ${ }^{15-17}$. Nevertheless, the use of specifically designed equipment and/or operating conditions remains a general limitation, and reagents that are easily handled but capable of slowly generating $\mathrm{CF}_{3} \mathrm{CHN}_{2}$ in situ under mild conditions (ideally complementing current oxidative/acidic methods) are of high appeal.

We targeted the use of trifluorinated N-sulfonylhydrazones as a trifluorodiazoethane surrogate. As a class of stable precursors to diazo compounds, sulfonylhydrazones are widely used in synthesis ${ }^{18-22}$; however, trifluoroacetaldehyde-derived sulfonylhydrazones have not been explored as surrogates for $\mathrm{CF}_{3} \mathrm{CHN}_{2}{ }^{23,24}$. gem-Difluoroalkenes are important motifs in the design of mechanism-based enzyme inhibitors, and as bioisosteres of the carbonyl group $25-27$, and are typically prepared by Wittig or Julia-Kocienski-type reactions $s^{28-30}$, or by cross-coupling $31-34$. However, these methods are mostly effective only for the synthesis of $C$-substituted gem-difluoroalkenes, while the synthesis of their heteroatom-substituted counterparts is comparatively rare and suffers from narrow substrate scope, or requires strong bases or toxic reagents ${ }^{35-39}$.

We report here the development of trifluoroacetaldehyde $\mathrm{N}$ tfsylhydrazone (TFHZ-Tfs) as a bench-stable $\mathrm{CF}_{3} \mathrm{CHN}_{2}$ precursor, which decomposes in a controlled manner under basic conditions to release $\mathrm{CF}_{3} \mathrm{CHN}_{2}$ into the reaction system (Fig. 1b); this strategy circumvents the need for slow addition or manual handling of $\mathrm{CF}_{3} \mathrm{CHN}_{2}$, thus minimizing exposure and reducing the potential explosion risk. Importantly, this base-mediated approach also led to the discovery of novel reactivity of $\mathrm{CF}_{3} \mathrm{CHN}_{2}$ : we describe its use in the difluoroalkenylation of $\mathrm{X}-\mathrm{H}$ $(\mathrm{X}=\mathrm{N}, \mathrm{O}, \mathrm{S}, \mathrm{Se})$ bonds, overcoming limitations in previous routes to these motifs, and also in Doyle-Kirmse and cyclopropanation reactions, which display excellent stereoselectivity and yields, and collectively demonstrate the potential utility of TFHZTfs as a trifluorodiazoethane surrogate.

\section{Results}

Synthesis of TFHZ-Tfs. TFHZ-Tfs could be easily accessed by condensation of the $o$-trifluoromethylbenzenesulfonyl hydrazide with trifluoroacetaldehyde monohydrate under acidic conditions. The reaction proved readily scalable, TFHZ-Tfs could be prepared in high yield (91\%) on $85 \mathrm{mmol}$ scale as a bench-stable crystalline solid, and in a cost-effective manner, which is attractive for synthetic applications. In addition, TFHZ-Tfs could be stored at ambient temperature for at least 5 months without degradation (as characterized by ${ }^{1} \mathrm{H}$ NMR spectroscopy).

Investigation of reaction conditions. An exploration of the reactivity of TFHZ-Tfs began in the difluoroalkenylation of $\mathrm{X}-\mathrm{H}$ bonds. $p$-Methylthiophenol was identified as a suitable nucleophile for this study, and to our delight we found that in the presence of aqueous $\mathrm{KOH}$, sodium dodecylbenzenesulfonate (SDBS, $30 \mathrm{~mol} \%$ ), and the iron porphyrin catalyst $\mathrm{FeTPPCl}$ ( $5 \mathrm{~mol} \%$ ) in dichloromethane at $40^{\circ} \mathrm{C}$, TFHZ-Tfs delivered the difluoroalkenylated product 2 in $51 \%$ yield, along with $9 \%$ of the trifluoroethyl thioether $\mathbf{2}^{\prime}$ (Fig. 2, Entry 1). Iron porphyrin complexes have been applied as highly efficient catalyst in carbene-transfer reactions ${ }^{40}$. Screening of other iron porphyrin complexes led to the discovery of the more robust $\mathrm{Fe}[\mathrm{P} 2]$ catalyst, which at just $1 \mathrm{~mol} \%$ loading afforded 2 in $80 \%$ isolated yield, while suppressing the formation of side product $2^{\prime}$ (Entries 2 and 3). Under the same conditions, TFHZ-Ns and TFHZ-Ts gave 2 in significantly lower yield (Entries 4 and 5). Additional optimization of this S-H gem-difluoroalkenylation led to refinement of the reactions parameters (Entry 3, TFHZ-Tfs (2.0 equiv), $5 \mathrm{~mL} \mathrm{KOH}$ aq. (20 wt\%), and SDBS (30 mol\%) in the presence of $1 \mathrm{~mol} \%$ of $\mathrm{Fe}[\mathrm{P} 2]$ in DCM at $40^{\circ} \mathrm{C}$ under air; see Supplementary Table 1 for details).

Scope of thiol gem-difluoroalkenylation. Having established the decomposition profile of TFHZ-Tfs, and conditions for thiol difluoroalkenylation, the scope of this insertion was explored. Under the optimized conditions of Fig. 2 Entry 3 (Method A), a broad tolerance of arene substituents was observed (Fig. 3), with thiophenols bearing both electron-donating and electronwithdrawing substituents giving the corresponding difluoroalkenes in good to excellent yields (2-19). Notably, reaction efficiency was not compromised by the positioning of the aryl substituent (ortho, meta, or para), and indeed sterically hindered mono- or bis-ortho-substituted substrates afforded the difluoroalkenes in high yields (20-21). Thienyl, furyl, and 2-naphthalene thiols were also excellent substrates, leading to heteroaryl- and naphthyl sulfides 22-24. We were pleased to find that benzeneselenol performed equally well, affording the selenodifluoroalkene 25 in 66\% yield. The difluoroalkenylated structure was unambiguously confirmed by single crystal X-ray diffraction analysis of sulfone $\mathbf{9}^{\prime}$, which was prepared by oxidation of $\mathbf{9}$ with $m$-CPBA (see Supplementary Table 7 for X-ray crystallographic data).

Scope of amine gem-difluoroalkenylation. We next questioned whether other heteroatoms could also serve as suitable nucleophilic coupling partners, and turned our attention to amine difluoroalkenylation. After extensive screening of reaction parameters, a copper catalyst system was identified that efficiently mediated this transformation, consisting of $\mathrm{Cu}(\mathrm{OTf})_{2}(20 \mathrm{~mol} \%)$ and $\mathrm{LiO} t-\mathrm{Bu}$ (4.0 equiv) in DCE:toluene (3:1) under argon at $40^{\circ} \mathrm{C}$ (Fig. 3, Method B, see Supplementary Table 2 for details of reaction optimization). The reaction scope encompassed a variety of aniline derivatives, with ring substituents including halides, nitriles, ketones, esters, and anthraquinones, delivering the gemdifluoroenamines in moderate to good yields (26-35). In some cases, incomplete conversions were observed, but the residual amine substrate could be recovered. In addition to primary anilines, benzophenone imine proved a viable substrate: product $\mathbf{3 6}$ was obtained in $51 \%$ yield, suggesting this method could be applied to the $\mathrm{N}$-difluoroalkenylation of other nitrogen-based nucleophiles. Secondary amines did not prove suitable, as shown by the low yield of compound 37 .

Scope of alcohol gem-difluoroalkenylation. Further expansion of the scope of the methodology was achieved through modification of the copper catalyst to enable the synthesis of difluorovinyl ethers from alcohols (Fig. 3, Method C, for details of optimization see Supplementary Table 3). A wide selection of benzyl-, alkyl-, and heteroaryl-substituted alcohols afforded gemdifluorovinyl ethers in good to excellent yields; for benzyl 
a Oxidation of trifluoroethylamine hydrochloride under acidic conditions (the sole method)

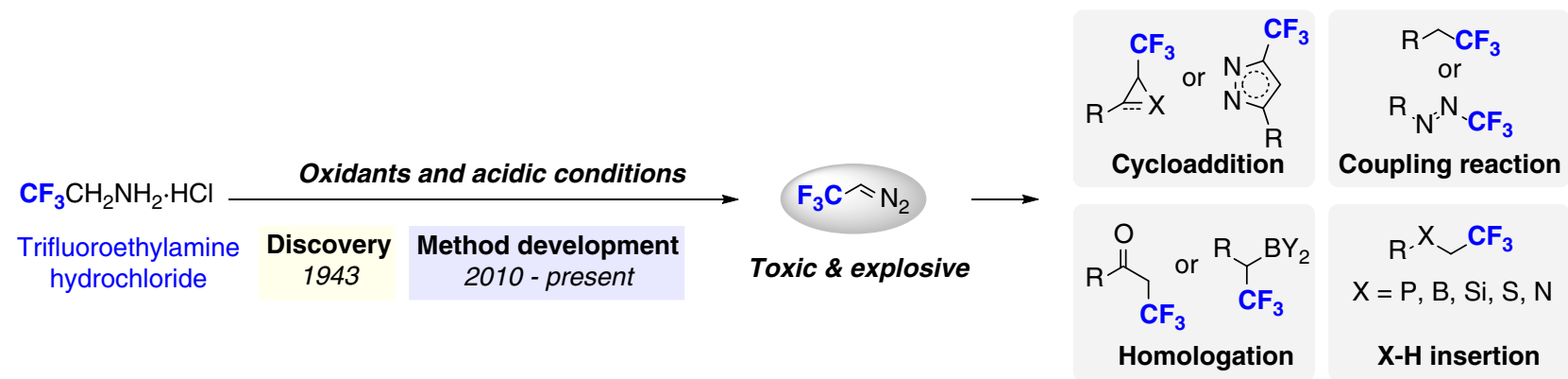

b Decomposition of trifluoroacetaldehyde $\mathrm{N}$-tfsylhydrazone (TFHZ-Tfs) under basic conditions (this work)

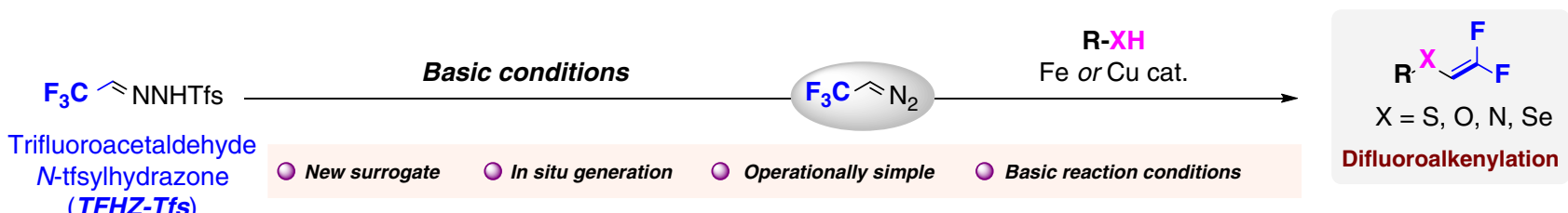

Fig. 1 Generation and transformations of trifluorodiazoethane, and synthesis of TFHZ-Tfs. a Synthesis and applications of trifluoromethyldiazomethane $\left(\mathrm{CF}_{3} \mathrm{CHN}_{2}\right)$ in organic synthesis. $\mathrm{CF}_{3} \mathrm{CHN}_{2}$ is a highly reactive trifluoroalkylation reagent, but its simplex synthesis method, inherent toxicity and explosiveness limit its widespread application. Because of its hazardous nature, manifold methods have been developed for the safer use of $\mathrm{CF}_{3} \mathrm{CHN}_{2}$ such as slow addition of oxidants, small-scale preparation of $\mathrm{CF}_{3} \mathrm{CHN}_{2}$ solution, recycling of gaseous $\mathrm{CF}_{3} \mathrm{CHN}_{2}$ and continuous-flow chemistry. $\mathbf{b}$ Method for the generation of $\mathrm{CF}_{3} \mathrm{CHN}_{2}$ from trifluoroacetaldehyde $\mathrm{N}$-tfsylhydrazone under basic condition and gem-difluoroalkenylation of $\mathrm{X}-\mathrm{H}$
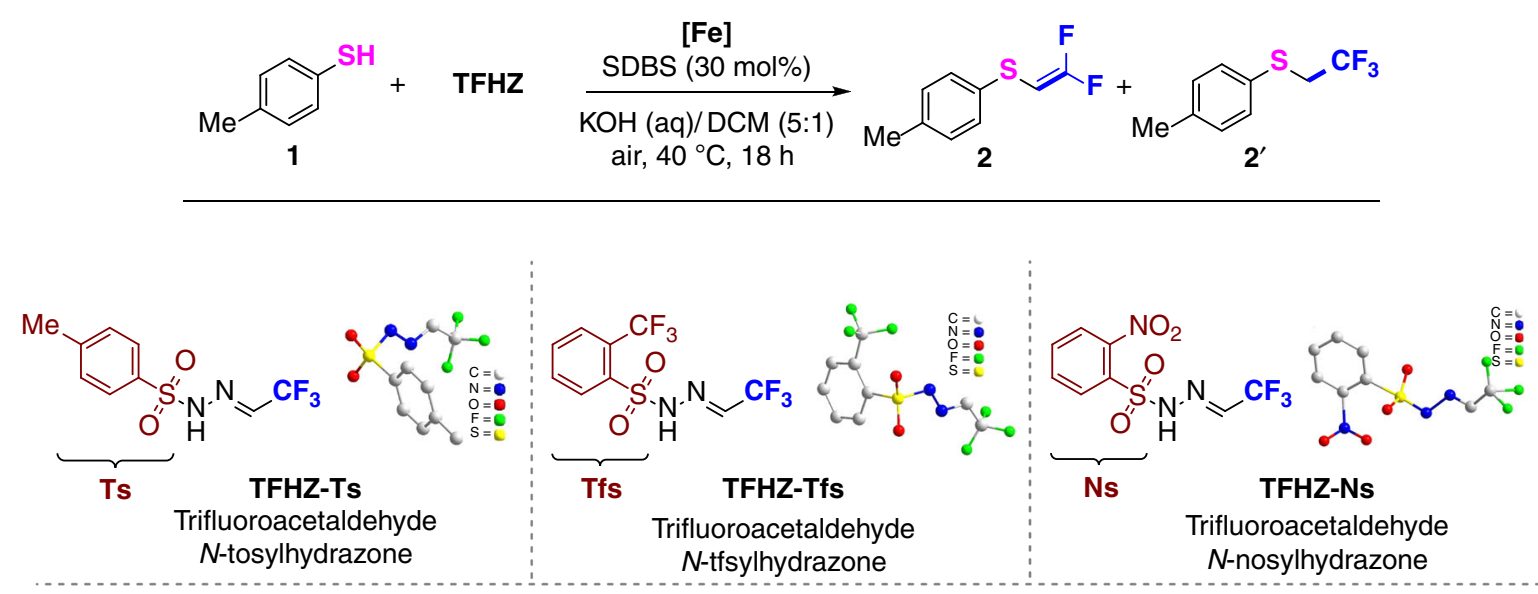

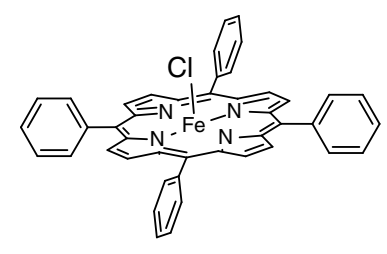

FeTPPCI

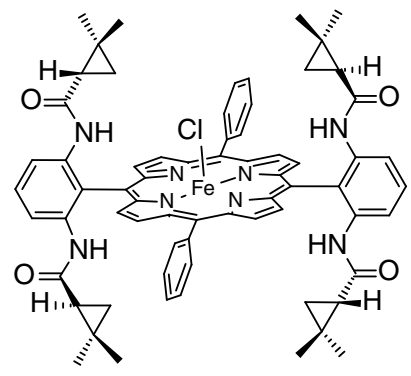

$\mathrm{Fe}[\mathrm{P} 1]$

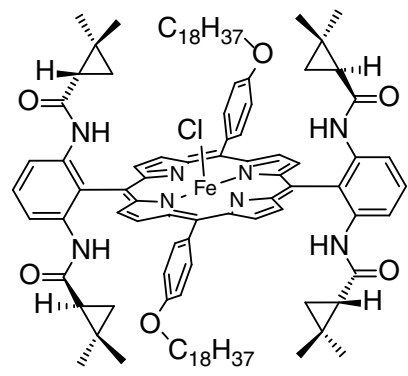

$\mathrm{Fe}[\mathrm{P} 2]$

Fig. 2 Optimization of the iron-catalyzed gem-difluoroalkenylation of $p$-methylthiophenol with trifluoromethyl sulfonylhydrazones. Reaction conditions: thiophenol $(0.3 \mathrm{mmol})$, sulfonylhydrazone $(0.6 \mathrm{mmol})$, Fe porphyrin catalyst, SDBS (sodium dodecylbenzenesulfonate) $(0.09 \mathrm{mmol}), \mathrm{DCM}(1.0 \mathrm{~mL})$, and $\mathrm{KOH}$ solution $\left(5.0 \mathrm{~mL}, 20 \%\right.$ wt \%), $40{ }^{\circ} \mathrm{C}, 18 \mathrm{~h}$, under air. ${ }^{a}$ Yields determined by ${ }^{1} \mathrm{H}$ NMR spectroscopic analysis with $\mathrm{CH}_{2} \mathrm{Br}_{2}$ as an internal standard. beaction carried out under Ar atmosphere. ${ }^{\mathrm{C}}$ Yield in parentheses is the isolated yield 


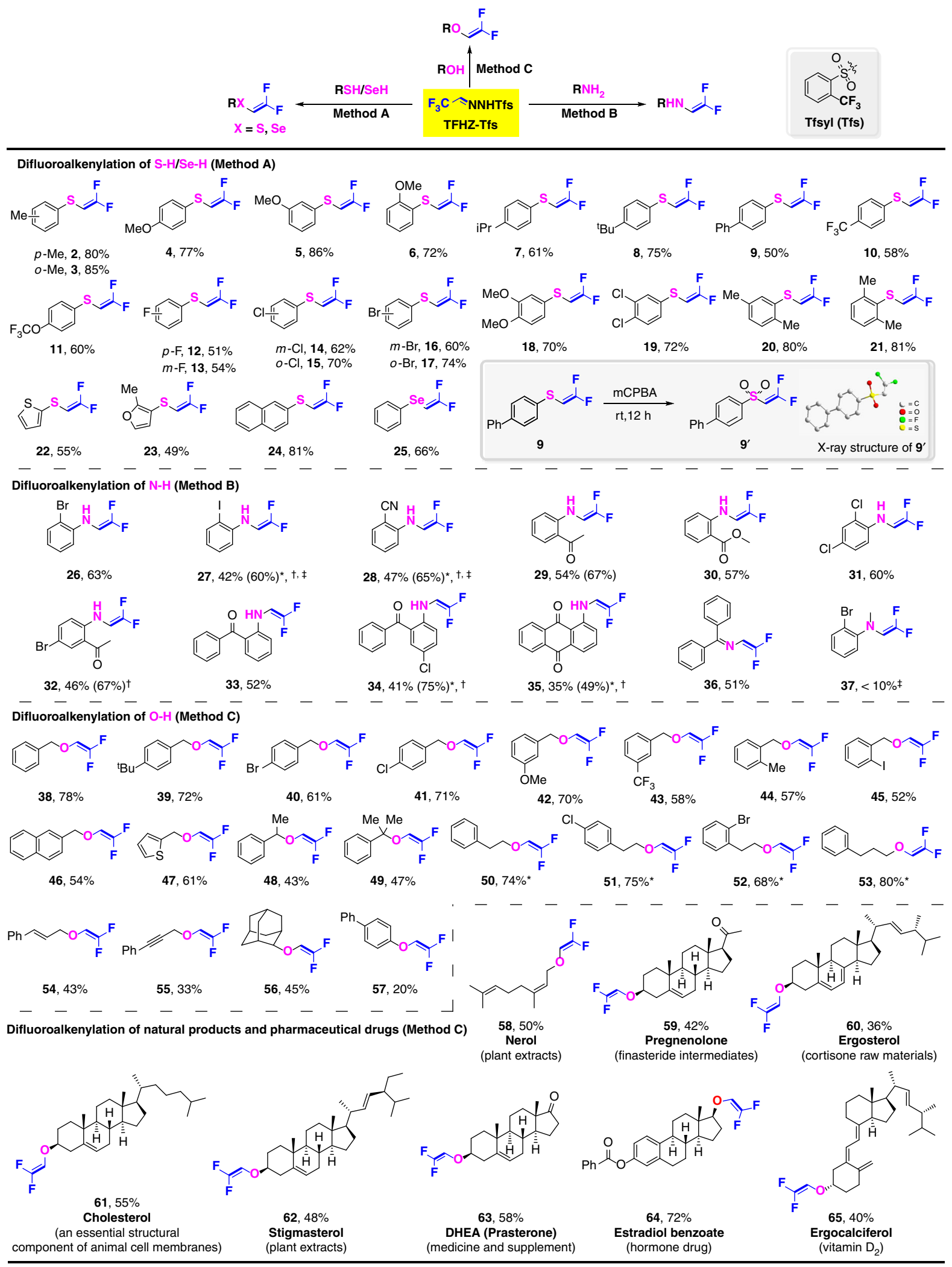

Fig. 3 Scope of gem-difluoroalkenylation of $X-H(X=N, O, S$, Se). Reaction conditions: Method A: thiophenol $(0.3 \mathrm{mmol})$, TFHZ-Tfs $(0.6 \mathrm{mmol})$, Fe[P2] (1 mol\%), SDBS (30 mol\%), KOH (aq.)/DCM (5:1), air, $40^{\circ} \mathrm{C}, 18 \mathrm{~h}$. Method B: amine $(0.3 \mathrm{mmol}), \mathrm{TFHZ}-\mathrm{Tfs}(0.6 \mathrm{mmol}), \mathrm{Cu}(\mathrm{OTf}){ }_{2}(20 \mathrm{~mol} \%), \mathrm{LiO}{ }^{t} \mathrm{Bu}$ (4 equiv), DCE: toluene (3:1), $\mathrm{Ar}, 40^{\circ} \mathrm{C}, 24 \mathrm{~h}$. Method C: TFHZ-Tfs ( $\left.1.0 \mathrm{mmol}\right), \mathrm{NaH}$ (4 equiv) and DCE ( $8.0 \mathrm{~mL}$ ) were stirred at rt for $1 \mathrm{~h}$ under Ar, then $\mathrm{CuBr}(30 \mathrm{~mol} \%)$, alcohol $(0.5 \mathrm{mmol})$, and $\mathrm{LiO}^{\mathrm{B}} \mathrm{Bu}$ (1 equiv) were added and the mixture was stirred at $40^{\circ} \mathrm{C}$ under $\mathrm{Ar}$ for $24 \mathrm{~h}$. ${ }^{*} \mathrm{Reaction}$ performed for $30 \mathrm{~h}$. N Number in parentheses is the yield based on recovered starting material (brsm). ${ }^{\dagger}$ The yield was determined by ${ }^{1} \mathrm{H}$ NMR spectroscopic analysis with $\mathrm{CH}_{2} \mathrm{Br}_{2}$ as an internal standard 
alcohols, the position of substituents on the arene had little influence on the reaction outcome (38-47), and secondary and tertiary benzyl alcohols also afforded the corresponding products with respectable efficiency (48 and 49). Alkyl alcohols (such as phenethyl and phenylpropyl), and other functionalized alcohols (such as cinnamyl, propargyl, and 2-adamantyl), all proved reactive partners, affording products $\mathbf{5 0 - 5 6}$ in moderate to high yields. In contrast to aliphatic alcohols, phenols showed poor reactivity; for example, 4-biphenylol gave the difluoroalkenylated product 57 in just $20 \%$ yield, which presumably reflects the poorer nucleophilicity of the phenol compared to the aliphatic substrate.

Scope of gem-difluoroalkenylation with bioactive molecules. To illustrate potential utility, the methodology was applied to the gem-difluoroalkenylation of selected natural products, drugs, and pharmaceutical intermediates. For instance, various terpene and steroid natural products (nerol, pregnenolone, ergosterol, cholesterol, and stigmasterol) were derivatized into the desired difluorovinyl ethers in good yields (58-63). Estradiol benzoate, a highly potent hormone therapy agent used to treat estrogen deficiencies, could also be converted to the corresponding gemdifluoroalkenylated product $\mathbf{6 4}$ in $72 \%$ yield. Further, the synthesis of gem-difluoroalkenylated vitamin $\mathrm{D}_{2} \mathbf{6 5}$, (the parent being a potent drug for treatment of cutaneous tuberculosis and lupus erythematosus), was achieved in the presence of its potentially sensitive triene functionality, underlining the functional group tolerance of this methodology. It is notable that fluoroalkyl ethers represent the key structure of many insecticides and lubricants; the ready availability of such gem-difluorovinyl ethers may provide new opportunities for the design and construction of such molecules 41 .

Gram-scale synthesis and further transformations. For multigram-scale applications, the $\mathrm{Fe}[\mathrm{P} 2]$ catalyst (which requires a multistep synthesis) could be conveniently replaced with the commercially available FeTPPC1 (Fig. 4). Using this alternative catalyst with dichloromethane as solvent, gem-difluorovinyl sulfide 9 was obtained in a yield of $47 \%$, which is comparable to that obtained with $\mathrm{Fe}[\mathrm{P} 2]$ (Method A, 50\%). Interestingly, this product could be smoothly mono-defluorinated by treatment with $\mathrm{CuCl}$ and $\mathrm{B}_{2}$ pin $_{2}$ to give the $(Z)$-monofluorovinyl sulfide 66 in $67 \%$ yield $^{42}$; to our knowledge, no other routes to selectively access such monofluorinated alkenyl thioethers are known. Alternative functionalization also proved possible, such as substitution of both fluorines in 9 by reaction with excess $p$-methoxyphenol in the presence of $\mathrm{NaH}$, affording the trisubstituted olefin 67 in $42 \%$ yield $^{43}$.

Mechanistic investigations. To gain insight into the reaction mechanism, a $\mathrm{CF}_{3} \mathrm{CHN}_{2}$ solution in dichloromethane was prepared according to previous reports (Fig. 5, Eq. 4) ${ }^{5}$, and then treated with 4-methylbenzenethiol under Method A, which led to 2 and $2^{\prime}$ in $48 \%$ and $3 \%$ yield respectively as detected by ${ }^{1} \mathrm{H}$ NMR analysis of the crude reaction mixture. However, if neutral water was used instead of aqueous $\mathrm{KOH}$, only $\mathbf{2}^{\prime}$ was obtained (61\%). These results suggest that base plays a crucial role in the gemdifluoroalkenylation reaction, in that it may either facilitate reaction of the heteroatomic nucleophile by deprotonation, and/ or may promote a $\beta$-F elimination of a reaction intermediate. To confirm that the trifluoroethyl sulfide $\mathbf{2}^{\prime}$ is indeed a side product rather than an intermediate, conversion of $\mathbf{2}^{\prime}$ into $\mathbf{2}$ under Method A was attempted, but without success (Eq. 5). This may imply that the reaction mechanism involves direct fluoride ion elimination from a carbenoid-derived species, rather than elimination of HF from the trifluoroethyl group. The observation that (2,2,2-trifluoroethoxy)methylbenzene $\mathbf{6 8}$ was also not converted to 38 under Method C (Eq. 6) supports this hypothesis.

Proposed mechanism. Based on these experimental results, a plausible reaction mechanism is proposed in Fig. 6 in which trifluorodiazoethane is generated in situ from TFHZ-Tfs under the basic reaction conditions, and then reacts with the metal catalyst to form carbenoid intermediate $\mathbf{A}$. The latter is trapped by the substrate (or deprotonated substrate) to form the oxonium ylide $\mathbf{B}^{44}$; Following deprotonation under the basic reaction conditions, the resultant intermediate $\mathbf{C}$ undergoes $\beta$-fluoride elimination to give the gem-difluoroalkenylation product, regenerating the metal catalyst ${ }^{34,45}$.

Applications of TFHZ-Tfs in Doyle-Kirmse reaction. The high efficiency observed in the difluoroalkenylation encouraged us to

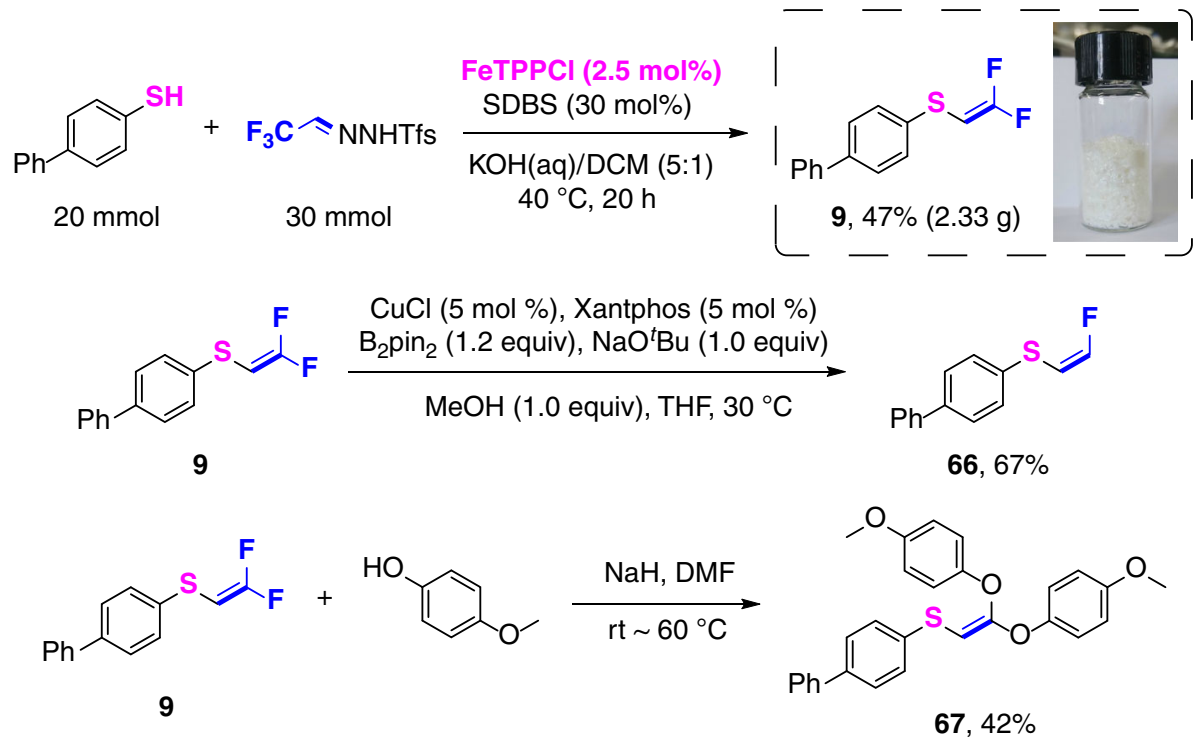

Fig. 4 Gram-scale synthesis and further transformations. Gram-scale synthesis of product $\mathbf{9}$ (1). Mono-defluorination of product 9 (2). Double defluorination of product $\mathbf{9}$ (3) 

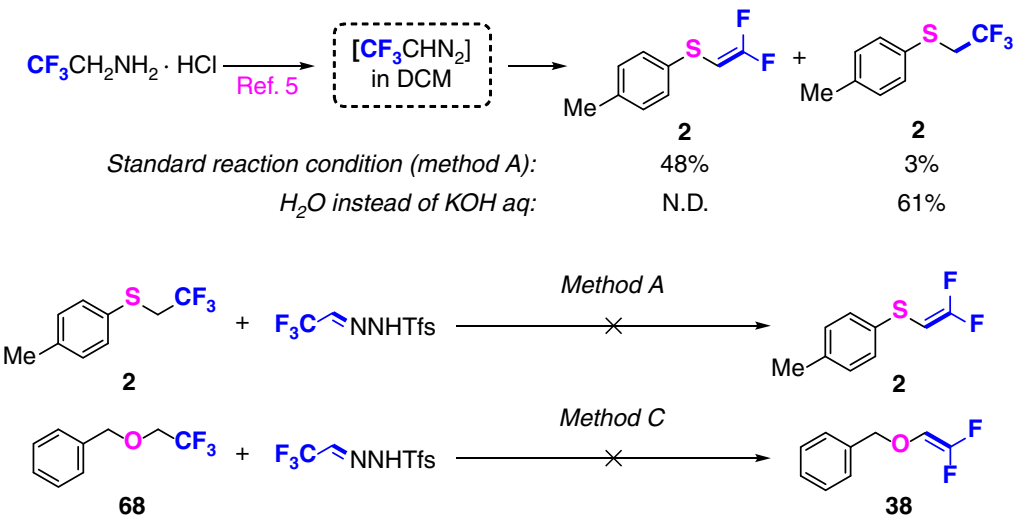

68

38

Fig. 5 Mechanistic investigations. Base promotes fluoride elimination (4) Intermediate experience verification (5) and (6)

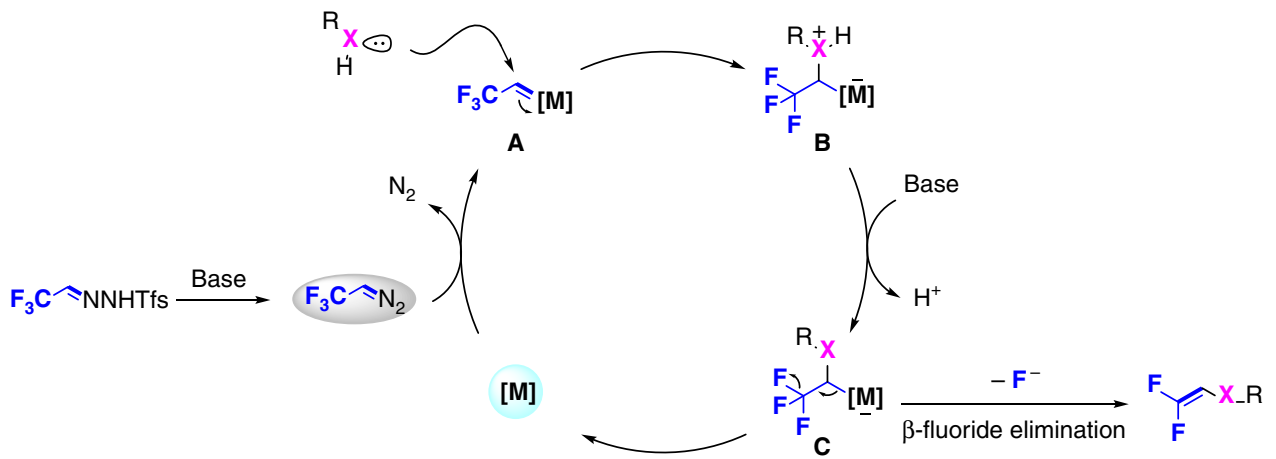

Fig. 6 Proposed mechanism. Mechanistic insights regarding to formation of oxonium ylide and fluoride elimination

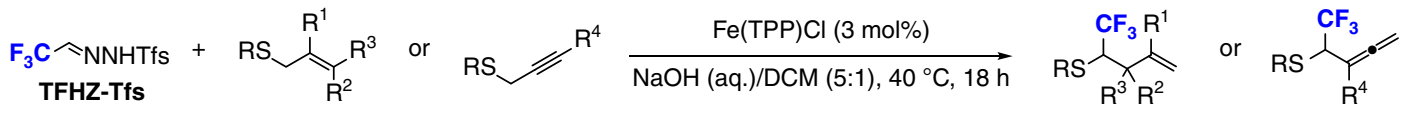<smiles>[R]c1ccc(SC(CC=C)C(F)(F)F)cc1</smiles>

69, $\mathrm{R}=\mathrm{H}, 92 \%$

70, $\mathrm{R}=\mathrm{Me}, 85 \%$

71, $\mathrm{R}={ }^{\mathrm{t}} \mathrm{Bu}, 87 \%$

72, $\mathrm{R}=\mathrm{OMe}, 95 \%$

73, $\mathrm{R}=\mathrm{Br}, 92 \%$

74, $\mathrm{R}=\mathrm{OCF}_{3}, 90 \%$

75, $\mathrm{R}=\mathrm{Ph}, 85 \%$

76, $\mathrm{R}=\mathrm{CF}_{3}, 86 \%$

77, $\mathrm{R}=\mathrm{NO}_{2}, 91 \%$<smiles>C=CCC(Sc1ccccc1P)C(F)(F)F</smiles>

78, $\mathrm{R}=\mathrm{Cl}, 89 \%$

79, $\mathrm{R}=\mathrm{Br}, 81 \%$

$80, \mathrm{R}=\mathrm{CO}_{2} \mathrm{Me}, 78 \%$<smiles>[R]c1cccc(SC(CC=C)C(F)(F)F)c1</smiles>

81, $R=F, 77 \%$

82, $\mathrm{R}=\mathrm{OMe}, 98 \%$

83, $\mathrm{R}=\mathrm{Me}, 94 \%$

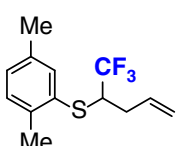

$84,84 \%$

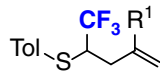

90, $\mathrm{R}^{1}=\mathrm{Me}, 76 \%$

91, $\mathrm{R}^{1}=\mathrm{Ph}, 72 \%$

92, $\mathrm{R}^{1}=\mathrm{Br}, 78 \%$

93, $\mathrm{R}^{1}=\mathrm{Cl}, 81 \%$<smiles>C=CCC(Sc1ccc2ccccc2c1)C(F)(F)F</smiles>

$85,80 \%$

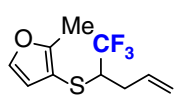

$86,75 \%$
次

$87,81 \%$<smiles>C=CCC(SC)C(F)(F)F</smiles>

$88,84 \%$<smiles>C=CCSC(CC=C)C(F)(F)F</smiles>

$89,82 \%$

\section{Propargyl thioethers}

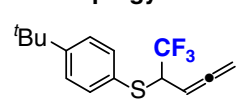

$100,78 \%$

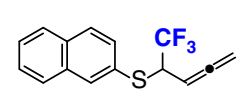

$101,70 \%$

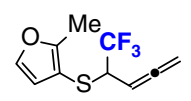

$102,64 \%$<smiles>[R]C(C=C)[C@@H](S[GaH])C(F)(F)F</smiles>

94, $R^{2}=$ Me, $75 \%(5: 1)$

95, $\mathrm{R}^{2}=\mathrm{Ph}, 72 \%(10: 1)$

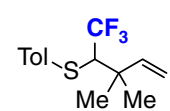

96, $90 \%$<smiles>C=C([Tl])C(C)[C@H](C)S[GaH]</smiles>

97, $\mathrm{R}^{1}=\mathrm{Me}, 71 \%(4: 1)$

98, $\mathrm{R}^{1}=\mathrm{Ph}, 68 \%(4: 1)$<smiles>FC(F)(F)[C@H](S[GaH])C1C=CCCC1</smiles>

$99,77 \%(7: 1)$

Fig. 7 Scope of Doyle-Kirmse reaction. Reaction conditions: thioether (0.3 mmol), TFHZ-Tfs (0.6 mmol), FeTPPCl (3 mol\%), NaOH (aq.)/DCM (5:1), $40^{\circ} \mathrm{C}, 18 \mathrm{~h}$

test the potential of this reagent in other carbenoid transformations. The Doyle-Kirmse reaction of allyl/propargyl thioethers was first studied, where we were delighted to find that reaction of TFHZ-Tfs with allylic thioethers catalyzed by $\mathrm{Fe}(\mathrm{TTP}) \mathrm{Cl}$ delivered the desired $\mathrm{CF}_{3}$-substituted homoallyl or alkenyl products in excellent yields (Fig. 7) ${ }^{46,47}$. This reaction offers a direct and powerful method for the construction of $\mathrm{C}\left(s p^{3}\right)-\mathrm{S}$ and $\mathrm{C}-\mathrm{C}$ bonds by [2,3]-sigmatropic rearrangement of diazo-derived ylids ${ }^{48,49}$, and again the use of TFHZ-Tfs proved superior for the generation of trifluorodiazoethane compared to the oxidation 
of trifluoroethylamine $e^{50}$. The scope of this reaction was found to be quite broad, with aryl thioethers containing electron-donating and electron-withdrawing groups at different positions of aryl ring affording $\mathrm{CF}_{3}$-substituted homoallyl products (69-83) in good to excellent yields. Thioethers bearing a disubstituted aryl group also proved suitable, such as a 2,5-dimethylated substituent, which gave product $\mathbf{8 4}$ in $84 \%$ yield. Naphthyl and heteroaryl allyl thioethers also proceeded efficiently to give the corresponding products $\mathbf{8 5}$ and $\mathbf{8 6}$ (80\% and 75\%, respectively). Alkyl allyl thioethers, including benzyl, methyl, and bisallyl substituents, were also well-tolerated to produce the desired products (87-89) in good yields.

Scope of Doyle-Kirmse reaction with allyl thioether. The effect of substituents $\left(R^{1}, R^{2}\right.$, and $\left.R^{3}\right)$ on the allyl thioether unit was similarly evaluated, which revealed that the substituent at the $2^{\prime}-$ position substituent on the allyl thioether unit $\left(\mathrm{R}^{1}\right)$ could be varied (methyl, phenyl, or halogen), giving products 90-93 with high efficiency. Equally, a range of 1,2-disubstituted allylic thioethers $\left(\mathrm{R}^{2}=\mathrm{Me} / \mathrm{Ph}, \mathrm{R}^{3}=\mathrm{H} / \mathrm{Me}\right)$ were compatible, affording products (94-98) with high stereoselectivity (up to 10:1 dr, absolute configuration of major isomers was unambiguously confirmed by single crystal X-ray diffraction analysis of its derivatives, details see Supplementary Table 8). Most noteworthy among these variations is the rearrangement to generate a quaternary carbon center in homoallylic sulfide 96. Moreover, a cyclic olefin-substituted thioether afforded the $S$-to- $C$ transposition product 99 in 77\% yield, with high stereoselectivity (7:1 $d r)$.

Scope of Doyle-Kirmse reaction with propargyl thioether. We next investigated the scope of the Doyle-Kirmse reaction using propargyl thioethers. Pleasingly, aryl, alkyl, fused aryl, and heteroaryl-functionalized propargyl thioethers all reacted smoothly with TFHZ-Tfs to give the expected allene products in good to excellent yields (100-103). Internal alkynyl thioethers exhibited outstanding reactivity, as demonstrated by reactions of methyl-, phenyl- and TMS-substituted propargyl thioethers, which gave products $104-106$ in $72-75 \%$ yield.

Applications of TFHZ-Tfs in cyclopropanation. Finally, the application of TFHZ-Tfs as a diazo precursor in cyclopropanation reactions was examined, with the aim of providing an alternative approach to medicinally-relevant trifluoromethylcyclopropanes ${ }^{2,51-55}$. To our delight, various terminal olefins underwent smooth reaction with TFHZ-Tfs under basic conditions in the presence of $\mathrm{Fe}(\mathrm{TPP}) \mathrm{Cl}$, giving the desired $\mathrm{CF}_{3}$-substituted cyclopropanes in high yields (Fig. 8). Good functional group tolerance and excellent stereoselectivity $(>20: 1)$ were observed: electron-neutral, -rich, and -poor styrenes all underwent efficient cyclopropanations, affording the corresponding trifluoromethylcyclopropane products 107-113 in $81-95 \%$ yields. Again, naphthyl and heteroaryl groups were accommodated, providing products $\mathbf{1 1 4}$ and $\mathbf{1 1 5}$ in $87 \%$ and $81 \%$ yields respectively. Other conjugated dienes and enynes were examined, and also generated the corresponding cyclopropanes (116-118) in excellent yields. Finally, the use of 1,1-disubstituted olefins was equally well-tolerated in spite of increased steric hindrance, delivering trisubstituted products 119 and 120 without diminishing the reaction efficiency or stereoselectivity.

\section{Discussion}

In summary, we report the development of trifluoroacetaldehyde $\mathrm{N}$-tfsylhydrazone (TFHZ-Tfs) - a bench-stable crystalline reagent that represents a versatile trifluorodiazoethane surrogate, which can generate $\mathrm{CF}_{3} \mathrm{CHN}_{2}$ under basic conditions in a controlled manner that avoids excessive buildup of the hazardous diazo compound. A number of applications of TFHZ-Tfs are described, including the discovery of gem-difluoroalkenylation of $\mathrm{X}-\mathrm{H}$ bonds $(\mathrm{X}=\mathrm{S}, \mathrm{N}, \mathrm{O}, \mathrm{Se})$, Doyle-Kirmse rearrangements, and trifluoromethylcyclopropanation reactions, with superior performance over other sources of $\mathrm{CF}_{3} \mathrm{CHN}_{2}$. Considering the procedural advantages of this trifluorodiazoethane surrogate, and the importance of generally applicable fluorination methodologies, these findings create many opportunities for the wider exploration of the chemistry of trifluorodiazoethane.

\section{Methods}

General procedure for the synthesis of gem-difluorovinyl thioether. A screw capped reaction vial was charged with TFHZ-Tfs $(0.6 \mathrm{mmol})$, toluenethiol $(0.3 \mathrm{mmol}), \mathrm{Fe}[\mathrm{P} 2](0.003 \mathrm{mmol})$ and SDBS (sodium dodecylbenzenesulphonate) $(0.09 \mathrm{mmol})$ under air, followed by addition of DCM $(1.0 \mathrm{~mL})$ and $\mathrm{KOH} a q$. $(5.0 \mathrm{~mL}, 20 \mathrm{wt} \%)$ (Fig. 5, Method A) . The resulting mixture was stirred at $40^{\circ} \mathrm{C}$ for $18 \mathrm{~h}$. Then $10 \mathrm{~mL}$ water was added to the mixture, which was extracted with DCM $(3 \times 10 \mathrm{~mL})$. The organic layer was combined and dried with anhydrous $\mathrm{MgSO}_{4}$, then filtered through a short silica gel eluting with DCM. The filtrate was evaporated under reduced pressure to leave a crude mixture, which was separated by flash column chromatography to afford the pure product.

General procedure for the synthesis of gem-difluorovinyl amine. A screw capped reaction vial was charged with TFHZ-Tfs $(0.6 \mathrm{mmol})$, amine $(0.3 \mathrm{mmol})$, $\mathrm{Cu}(\mathrm{OTf})_{2}(0.06 \mathrm{mmol})$ and $\mathrm{LiO}^{t} \mathrm{Bu}(1.2 \mathrm{mmol})$, then evacuated and filled with argon for three times, followed by addition of DCE $(3.0 \mathrm{~mL})$ and toluene $(1.0 \mathrm{~mL})$ via syringe (Fig. 5, Method B). The resulting mixture was stirred at $40^{\circ} \mathrm{C}$ for $24 \mathrm{~h}$. The reaction crude was filtered through a short silica gel eluting with DCM. The filtrate was evaporated under reduced pressure to leave a crude mixture, which was separated by flash column chromatography to afford the pure product.

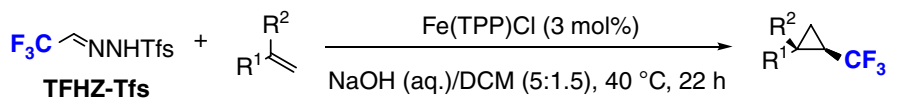

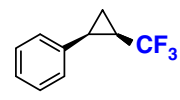

$107,92 \%$<smiles>FC(F)(F)C1CC1c1ccc2ccccc2c1</smiles>

$114,87 \%$<smiles>COc1ccc(CC(F)(F)F)cc1</smiles>

108, $91 \%$<smiles></smiles>

$115,83 \%$<smiles>FC(F)(F)Cc1ccc(-c2ccccc2)cc1</smiles>

$109,90 \%$<smiles>COc1ccc(C=CCC(F)(F)F)cc1</smiles>

116, $93 \%$<smiles>FC(F)(F)Cc1ccc(C(F)(F)F)cc1</smiles>

$110,81 \%$<smiles>CC(=Cc1ccccc1)CC(C)CC(F)(F)F</smiles>

$117,78 \%$<smiles>N#Cc1ccc(CC(F)(F)F)cc1</smiles><smiles>FC(F)(F)Cc1cccc(Br)c1</smiles>

112, $87 \%$

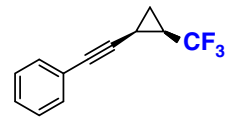

118, $91 \%$<smiles>FC(F)(F)C1CC1(P)c1ccccc1</smiles>

$119,94 \%$

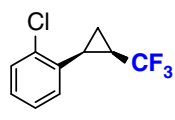

113, $95 \%$

Fig. 8 Scope of trifluoromethylcyclopropanation. Reaction conditions: olefin (0.3 mmol), TFHZ-Tfs (0.6 mmol), FeTPPCl (3 mol\%), NaOH (aq.)/DCM $(5: 1.5), 40^{\circ} \mathrm{C}, 22 \mathrm{~h}$ 
General procedure for the synthesis of gem-difluorovinyl ether. A screw capped reaction vial was charged with TFHZ-Tfs $(1.0 \mathrm{mmol}$ ), and $\mathrm{NaH}$ (60 wt $\%$, $2 \mathrm{mmol}$ ) and was evacuated and filled with argon for three times, followed by addition of dry DCE $(8.0 \mathrm{~mL})$ via syringe. The resulting mixture was stirred at room temperature for $1 \mathrm{~h}$ (Fig. 5, Method C). Then, alcohol $(0.5 \mathrm{mmol})$ and $\mathrm{CuBr}$ $(0.15 \mathrm{mmol})$ were added and the system was stirred at $40^{\circ} \mathrm{C}$ for $24 \mathrm{~h}$. The reaction crude was filtered through a short silica gel eluting with DCM. The filtrate was evaporated under reduced pressure to leave a crude mixture, which was purified by column chromatography on silica gel.

General procedures for Doyle-Kirmse reaction. A screw capped reaction vial was charged with TFHZ-Tfs $(0.6 \mathrm{mmol})$, FeTPPCl $(0.009 \mathrm{mmol})$, then evacuated and filled with argon for three times, then DCM $(1 \mathrm{~mL})$ which dissolved with allyl or propargyl sulfide $(0.3 \mathrm{mmol})$ and $\mathrm{NaOH}$ aq. $(5 \mathrm{~mL}, 20 \mathrm{wt} \%)$ was successively added by syringe (Fig. 7). The reaction was stirred at $40^{\circ} \mathrm{C}$ for $18 \mathrm{~h}$. Then $10 \mathrm{~mL}$ water was added to the mixture and layers partitioned. The aqueous layer was extracted with DCM $(3 \times 10 \mathrm{~mL})$ and the organic layer was combined and dried with anhydrous $\mathrm{MgSO}_{4}$, then filtered through a short silica gel eluting with DCM. The filtrate was evaporated under reduced pressure to leave a crude mixture, which was purified through silica gel flash column chromatography eluting with $n$-hexane to give the final product.

General procedures for cyclopropanation reaction. A screw capped reaction vial was charged with TFHZ-Tfs $(0.6 \mathrm{mmol})$, FeTPPCl $(0.009 \mathrm{mmol})$, then evacuated and filled with argon for three times, then DCM $(1.5 \mathrm{~mL})$ which dissolved with styrene $(0.3 \mathrm{mmol})$ and $\mathrm{NaOH}$ aq. $(5 \mathrm{~mL}, 20 \mathrm{wt} \%)$ was successively added by syringe (Fig. 8). The reaction was stirred at $40^{\circ} \mathrm{C}$ for $22 \mathrm{~h}$. Then $10 \mathrm{~mL}$ water was added to the mixture and layers partitioned. The aqueous layer was extracted with DCM $(3 \times 10 \mathrm{~mL})$ and the organic layer was combined and dried with anhydrous $\mathrm{MgSO}_{4}$, then filtered through a short silica gel eluting with DCM. The filtrate was evaporated under reduced pressure to leave a crude mixture, which was purified through silica gel flash column chromatography eluting with $n$-hexane to give the final cyclopropane product.

\section{Data availability}

The authors declare that all the data supporting the findings of this study are available within the paper and its supplementary information files, or from the corresponding author upon request. The X-ray crystallographic coordinates for structures reported in this article have been deposited at the Cambridge Crystallographic Data Center (Trifluoroacetaldehyde N-tfsylhydrazone: CCDC 1814685, Trifluoroacetaldehyde N-tosylhydrazone: CCDC 1814683, Trifluoroacetaldehyde N-nosylhydrazone: CCDC 1827227, 9': CCDC 1814506, 95': CCDC 1881268). These data could be obtained free of charge from The Cambridge Crystallographic Data Center via https://www.ccdc.cam.ac.uk/structures/.

Received: 15 October 2018 Accepted: 19 December 2018

Published online: 17 January 2019

\section{References}

1. Mertens, L. \& Koenigs, R. M. Fluorinated diazoalkanes-a versatile class of reagents for the synthesis of fluorinated compounds. Org. Biomol. Chem. 14, 10547-10556 (2016)

2. Morandi, B. \& Carreira, E. M. Iron-catalyzed cyclopropanation with trifluoroethylamine hydrochloride and olefins in aqueous media: in situ generation of trifluoromethyl diazomethane. Angew. Chem. Int. Ed. 49, 938-941 (2010).

3. Morandi, B. \& Carreira, E. M. Rhodium-catalyzed cyclopropenation of alkynes: synthesis of trifluoromethyl-substituted cyclopropenes. Angew. Chem. Int. Ed. 49, 4294-4296 (2010).

4. Künzi, S. A., Morandi, B. \& Carreira, E. M. Preparation of trifluoromethylsubstituted aziridines with in situ generated $\mathrm{CF}_{3} \mathrm{CHN}_{2}$. Org. Lett. 14, 1900-1901 (2012).

5. Li, F., Nie, J., Sun, L., Zheng, Y. \& Ma, J. A. Silver-mediated cycloaddition of alkynes with $\mathrm{CF}_{3} \mathrm{CHN}_{2}$ : highly regioselective synthesis of 3 trifluoromethylpyrazoles. Angew. Chem. Int. Ed. 52, 6255-6258 (2013).

6. Chen, Z., Zheng, Y. \& Ma, J. A. Use of a traceless activating and directing group for the construction of trifluoromethylpyrazoles: one-pot transformation of nitroolefins and trifluorodiazoethane. Angew. Chem. Int. Ed. 56, 4569-4574 (2017).

7. Luo, H., Wu, G., Zhang, Y. \& Wang, J. Silver(I)-Catalyzed Ntrifluoroethylation of anilines and $o$-trifluoroethylation of amides with 2,2,2trifluorodiazoethane. Angew. Chem. Int. Ed. 54, 14503-14507 (2015).

8. Hyde, S. et al. Copper-catalyzed insertion into heteroatom-hydrogen bonds with trifluorodiazoalkanes. Angew. Chem. Int. Ed. 55, 3785-3789 (2016).
9. Liu, C. B. et al. A facile parallel synthesis of trifluoroethyl-substituted alkynes Angew. Chem. Int. Ed. 51, 6227-6230 (2012).

10. Arkhipov, A. V., Arkhipov, V. V., Cossy, J., Kovtunenko, V. O. \& Mykhailiuk, P. K. Unexpected reactivity of trifluoromethyl diazomethane $\left(\mathrm{CF}_{3} \mathrm{CHN}_{2}\right)$ : electrophilicity of the terminal $\mathrm{N}$-atom. Org. Lett. 18, 3406-3409 (2016).

11. Argintaru, O. A., Ryu, D., Aron, I. \& Molander, G. A. Synthesis and applications of alpha-trifluoromethylated alkylboron compounds. Angew. Chem. Int. Ed. 52, 13656-13660 (2013).

12. Molander, G. A. \& Ryu, D. Diastereoselective synthesis of vicinally bis (trifluoromethylated) alkylboron compounds through successive insertions of 2,2,2-trifluorodiazoethane. Angew. Chem. Int. Ed. 53, 14181-14185 (2014)

13. National Research Council. Prudent Practices in the Laboratory: Handling and Management of Chemical Hazards, Updated Version. (The National Academies Press, Washington, DC, 2011).

14. Gilman, H. \& Jones, R. G. 2,2,2-Trifluoroethylamine and 2,2,2trifluorodiazoethane. J. Am. Chem. Soc. 65, 1458-1460 (1943).

15. Britton, J. \& Jamison, T. F. A unified continuous flow assembly-line synthesis of highly substituted pyrazoles and pyrazolines. Angew. Chem. Int. Ed. 56, 8823-8827 (2017).

16. Pieber, B. \& Kappe, C. O. Generation and synthetic application of trifluoromethyl diazomethane utilizing continuous flow technologies. Org. Lett. 18, 1076-1079 (2016).

17. Mertens, L., Hock, K. J. \& Koenigs, R. M. Fluoroalkyl-substituted diazomethanes and their application in a general synthesis of pyrazoles and pyrazolines. Chem. Eur. J. 22, 9542-9545 (2016).

18. Barluenga, J. \& Valdés, C. Tosylhydrazones: new uses for classic reagents in palladium-catalyzed cross-coupling and metal-free reactions. Angew. Chem. Int. Ed. 50, 7486-7500 (2011).

19. Xia, Y. \& Wang, J. N-tosylhydrazones: versatile synthons in the construction of cyclic compounds. Chem. Soc. Rev. 46, 2306-2362 (2017).

20. Zhang, Z. et al. Catalytic asymmetric trifluoromethylthiolation via enantioselective [2,3]-sigmatropic rearrangement of sulfonium ylides. Nat. Chem. 9, 970-976 (2017)

21. Battilocchio, C. et al. Iterative reactions of transient boronic acids enable sequential C-C bond formation. Nat. Chem. 8, 360-367 (2016).

22. Barluenga, J., Tomás-Gamasa, M., Aznar, F. \& Valdés, C. Metal-free carbon-carbon bond-forming reductive coupling between boronic acids and tosylhydrazones. Nat. Chem. 1, 494-499 (2009).

23. Lin, G.-q, Lei, X., Liu, P., Xu, Q.-Q. \& Dong, C. A complementary approach to 3,5-substituted pyrazoles with tosylhydrazones and terminal alkynes mediated by TfOH. Synlett 23, 2087-2092 (2012).

24. Crespin, L., Biancalana, L., Morack, T., Blakemore, D. C. \& Ley, S. V. One-pot acid-catalyzed ring-opening/cyclization/oxidation of aziridines with $\mathrm{N}$ tosylhydrazones: access to 1,2,4-triazines. Org. Lett. 19, 1084-1087 (2017).

25. Moore, W. R., Schatzman, G. L., Jarvi, E. T., Gross, R. S. \& McCarthy, J. R. Terminal difluoro olefin analogs of squalene are time-dependent inhibitors of squalene epoxidase. J. Am. Chem. Soc. 114, 360-361 (1992).

26. Motherwell, W. B., Tozer, M. J. \& Ross, B. C. A convenient method for replacement of the anomeric hydroxy group in carbohydrates by difluoromethyl functionality. J. Chem. Soc. Chem. Commun. 1437-1439 (1989).

27. Gouverneur, V. Fluorine in Pharmaceutical and Medicinal Chemistry: From Biophysical Aspects to Clinical Applications (World Scientific, Singapore, 2012).

28. Burton, D. J., Yang, Z.-Y. \& Qiu, W. Fluorinated ylides and related compounds. Chem. Rev. 96, 1641-1716 (1996).

29. Zhao, Y., Huang, W., Zhu, L. \& Hu, J. Difluoromethyl 2-pyridyl sulfone: a new gem-difluoroolefination reagent for aldehydes and ketones. Org. Lett. 12, 1444-1447 (2010).

30. Zheng, J., Cai, J., Lin, J.-H., Guo, Y. \& Xiao, J.-C. Synthesis and decarboxylative Wittig reaction of difluoromethylene phosphobetaine. Chem. Commun. 49, 7513-7515 (2013).

31. Ohashi, M. et al. Palladium-Catalyzed coupling reactions of tetrafluoroethylene with arylzinc compounds. J. Am. Chem. Soc. 133, 3256-3259 (2011).

32. $\mathrm{Hu}, \mathrm{M}$. et al. Copper-Catalyzed gem-difluoroolefination of diazo compounds with $\mathrm{TMSCF}_{3}$ via C-F bond cleavage. J. Am. Chem. Soc. 135, 17302-17305 (2013).

33. Hu, M., Ni, C., Li, L., Han, Y. \& Hu, J. gem-Difluoroolefination of diazo compounds with $\mathrm{TMSCF}_{3}$ or $\mathrm{TMSCF}_{2} \mathrm{Br}$ : transition-metal-free cross-coupling of two carbene precursors. J. Am. Chem. Soc. 137, 14496-14501 (2015).

34. Wu, G. et al. Switchable 2,2,2-trifluoroethylation and gem-difluorovinylation of organoboronic acids with 2,2,2-trifluorodiazoethane. Eur. J. Org. Chem. 2014, 4477-4481 (2014).

35. Piettre, S., De Cock, C., Merenyi, R. \& Viehe, H. G. Synthesis of fluorinated vinyl sulfides and selenides. Tetrahedron 43, 4309-4319 (1987).

36. Andrews, K. G., Faizova, R. \& Denton, R. M. A practical and catalyst-free trifluoroethylation reaction of amines using trifluoroacetic acid. Nat. Commun. 8, 15913 (2017) 
37. Decostanzi, M., Campagne, J. M. \& Leclerc, E. Fluorinated enol ethers: their synthesis and reactivity. Org. Biomol. Chem. 13, 7351-7380 (2015).

38. Zhang, D., Liu, H., Zhu, P., Meng, W. \& Huang, Y. One-pot syntheses of $\mathrm{N}$-(a-fluorovinyl)azole derivatives from $\mathrm{N}$-(diphenylmethylene)-2,2,2trifluoroethanamine. RSC Adv. 6, 73683-73691 (2016).

39. McCune, C. D. et al. Synthesis and deployment of an elusive fluorovinyl cation equivalent: access to quaternary $\alpha$-( $1^{\prime}$-fluoro)vinyl amino acids as potential PLP enzyme inactivators. J. Am. Chem. Soc. 139, 14077-14089 (2017).

40. Lu, H. \& Zhang, X. P. Catalytic C-H functionalization by metalloporphyrins: recent developments and future directions. Chem. Soc. Rev. 40, 1899-1909 (2011).

41. Ohashi, M., Adachi, T., Ishida, N., Kikushima, K. \& Ogoshi, S. Synthesis and reactivity of fluoroalkyl copper complexes by the oxycupration of tetrafluoroethylene. Angew. Chem. Int. Ed. 56, 11911-11915 (2017).

42. Kojima, R., Kubota, K. \& Ito, H. Stereodivergent hydrodefluorination of gem-difluoroalkenes: selective synthesis of (Z)- and (E)-monofluoroalkenes. Chem. Commun. 53, 10688-10691 (2017).

43. Moody, J. D., VanDerveer, D., Smith, D. W. Jr \& Iacono, S. T. Synthesis of internal fluorinated alkenesvia facile aryloxylation of substituted phenols with aryl trifluorovinyl ethers. Org. Biomol. Chem. 9, 4842-4849 (2011).

44. Guo, X. \& Hu, W. Novel multicomponent reactions via trapping of protic onium ylides with electrophiles. Acc. Chem. Res. 46, 2427-2440 (2013).

45. Prakash, G. K. et al. Long-lived trifluoromethanide anion: a key intermediate in nucleophilic trifluoromethylations. Angew. Chem. Int. Ed. 53, 11575-11578 (2014).

46. Lee, K. et al. Catalytic enantioselective addition of organoboron reagents to fluoroketones controlled by electrostatic interactions. Nat. Chem. 8, 768-777 (2016).

47. Wang, F. et al. Divergent synthesis of $\mathrm{CF}_{3}$-substituted allenyl nitriles by ligand-controlled radical 1,2- and 1,4-addition to 1,3-enynes. Angew. Chem. Int. Ed. 57, 7140-7145 (2018).

48. Reggelin, M. in Sulfur-Mediated Rearrangements II (ed. Ernst Schaumann) 1-65 (Springer, Berlin, Heidelberg, 2007).

49. West, T. H., Spoehrle, S. S. M., Kasten, K., Taylor, J. E. \& Smith, A. D. Catalytic stereoselective [2,3]-rearrangement reactions. ACS Catal. 5, 7446-7479 (2015).

50. Hock, K. J., Mertens, L., Hommelsheim, R., Spitzner, R. \& Koenigs, R. M. Enabling iron catalyzed Doyle-Kirmse rearrangement reactions with in situ generated diazo compounds. Chem. Commun. 53, 6577-6580 (2017).

51. Morandi, B., Mariampillai, B. \& Carreira, E. M. Enantioselective cobaltcatalyzed preparation of trifluoromethyl-substituted cyclopropanes. Angew. Chem. Int. Ed. 50, 1101-1104 (2011)

52. Tinoco, A., Steck, V., Tyagi, V. \& Fasan, R. Highly diastereo- and enantioselective synthesis of trifluoromethyl-substituted cyclopropanes via myoglobin-catalyzed transfer of trifluoromethylcarbene. J. Am. Chem. Soc. 139, 5293-5296 (2017).

53. Kotozaki, M., Chanthamath, S., Fujii, T., Shibatomi, K. \& Iwasa, S. Highly enantioselective synthesis of trifluoromethyl cyclopropanes by using Ru (ii)-Pheox catalysts. Chem. Commun. 54, 5110-5113 (2018).
54. Grygorenko, O. O., Artamonov, O. S., Komarov, I. V. \& Mykhailiuk, P. K. Trifluoromethyl-substituted cyclopropanes. Tetrahedron 67, 803-823 (2011).

55. Bos, M., Poisson, T., Pannecoucke, X., Charette, A. B. \& Jubault, P. Recent progress toward the synthesis of trifluoromethyl- and difluoromethylsubstituted cyclopropanes. Chem. Eur. J. 23, 4950-4961 (2017).

\section{Acknowledgements}

Financial support by NSFC $(21871043,21522202,21502017)$ and Department of Science and Technology of Jilin Province (20180101185JC, 20190701012GH). EAA thanks the EPSRC for support (EP/M019195/1).

\section{Author contributions}

X.Z. and Z.L. contributed equally to this work. X.Z., Z.L., X.Y., and Y.D. performed the experiments. M.V. and G.Z. conducted mechanistic studies. E.A.A. participated in the discussion of the research results as well as the revision of the manuscript. X.Z. and X.B. wrote the manuscript.

\section{Additional information}

Supplementary Information accompanies this paper at https://doi.org/10.1038/s41467 018-08253-z.

Competing interests: The authors declare no competing interests.

Reprints and permission information is available online at http://npg.nature.com/ reprintsandpermissions/

Journal peer review information: Nature Communications thanks the anonymous reviewers for their contribution to the peer review of this work. Peer reviewer reports are available.

Publisher's note: Springer Nature remains neutral with regard to jurisdictional claims in published maps and institutional affiliations.

(c) (i) Open Access This article is licensed under a Creative Commons C. Attribution 4.0 International License, which permits use, sharing, adaptation, distribution and reproduction in any medium or format, as long as you give appropriate credit to the original author(s) and the source, provide a link to the Creative Commons license, and indicate if changes were made. The images or other third party material in this article are included in the article's Creative Commons license, unless indicated otherwise in a credit line to the material. If material is not included in the article's Creative Commons license and your intended use is not permitted by statutory regulation or exceeds the permitted use, you will need to obtain permission directly from the copyright holder. To view a copy of this license, visit http://creativecommons.org/ licenses/by/4.0\%

(C) The Author(s) 2019 